\title{
Think beyond the cell: Can we [tissue] engineer a solution to heart failure?
}

\author{
Jason J. Han, MD, and Pavan Atluri, MD
}

\footnotetext{
From the Division of Cardiovascular Surgery, Department of Surgery, University of Pennsylvania, Philadelphia, $\mathrm{Pa}$.

Disclosures: Authors have nothing to disclose with regard to commercial support.

Received for publication Jan 27, 2018; accepted for publication Jan 31, 2018; available ahead of print March 3 , 2018.

Address for reprints: Pavan Atluri, MD, Division of Cardiovascular Surgery, Hospital of the University of Pennsylvania, 3400 Spruce St, 6 Silverstein Pavilion, Philadelphia, PA 19104 (E-mail: Pavan.Atluri@uphs.upenn. edu).

J Thorac Cardiovasc Surg 2018;156:227-8

$0022-5223 / \$ 36.00$

Copyright (C) 2018 by The American Association for Thoracic Surgery

https://doi.org/10.1016/j.jtcvs.2018.01.078
}

The relentless progression of coronary artery disease to ischemic heart failure is one of the leading causes of mortality and morbidity in America. Although macrorevascularization strategies offer immediate reperfusion benefits for some, challenges remain in mitigating adverse remodeling and maximizing myocardial function after injury., Delivery of various cell-based and molecular mechanisms directly onto the myocardium have been proposed, with varied efficacies in promoting angiogenesis and preservation of structure. $^{3-5}$ This rapidly growing field foreshadows an imminent inflection point in the treatment paradigm of heart failure-from stabilizing disease progression to reversing it entirely.

The article by Uchinaka and colleagues ${ }^{6}$ in this issue of the Journal comes at this opportune junction. Their experimental design was predicated on our understanding of myocardial contractility and extracellular matrix composition, namely the protective role of collagen type III (Col3) relative to collagen type I in both systolic and diastolic function after infarction and in tissue viscoelasticity. ${ }^{7} \mathrm{Col} 3$, which can be produced and delivered in large quantities or induced in vivo, offers an attractive option for the future of tissue engineering. The strength of this work is consistency, a hypothesis withstanding both direct application of Col3-secreting fibroblast sheets as well as the administration of the functional motif of N-terminal osteopontin fragment. For their modest group sizes, the consistency in the findings of Uchinaka and colleagues ${ }^{6}$ is relatively impressive, both in their histologic findings and in serial echocardiographic measurements, such that they were able to detect statistical significance in minor differences in cardiac function. Their values remain logical across all time points, possibly hinting at some longitudinal benefits of Col3 overexpression that extend well beyond the initial therapeutic period, delineating a narrative of efficacy that supports the initial hypothesis. There is strength in correlation of functional and immunohistologic evidence, with Uchinaka and

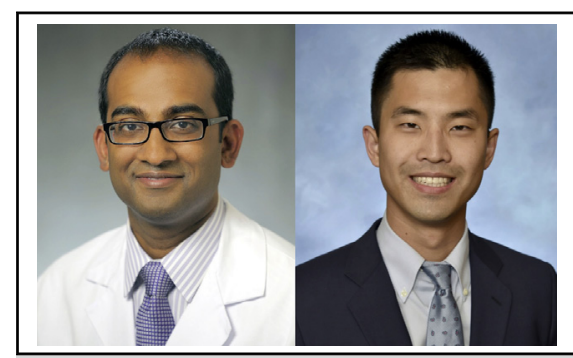

Pavan Atluri, MD (leff), and Jason J. Han, MD (right)

\section{Central Message}

Altering collagen expression may lead to favorable remodeling benefits and improved contractile function in a rodent ischemic heart failure model.

See Article page 217.

colleagues ${ }^{6}$ noting increased distribution of Col3 in the treatment group and reduced scar size correlating with reduced eccentric cardiac remodeling, as evidenced by left ventricular chamber diameter, ejection fraction, and fractional shortening.

Although the use of Col3-overexpressing fibroblast sheets offers mechanistic validation, Uchinaka and colleagues ${ }^{6}$ may encounter inherent limitations in the use of cell-based therapy as a result of limited cell retention, proliferation, and viability. ${ }^{8}$ Incorporation of the N-terminal osteopontin fragment into a delivery gel with collagenasedependent sustained-release properties offers an attractive alternative, as evidenced by the longitudinal echocardiographic benefits out to 8 weeks after implantation. Still, as we have learned from countless trials, our enthusiasm should be tempered. Often the translation from small animal to large animal and ultimately to clinical therapy may not result in clinically significant benefits. Preliminarily, the small animal data are encouraging, and we look forward to the translatability of these mechanisms in future large animal studies, particularly with regard to the scale of the benefits in contractile function and the clinical significance.

Overall, Uchinaka and colleagues ${ }^{6}$ deserve our congratulations for their important contributions to the robust field of tissue-engineering in heart failure. Clever designs to alter the ratio of collagen type I and $\mathrm{Col} 3$, such as those studied here and surely to follow in future endeavors, may offer the intuitive and innovative solutions to adverse remodeling that our patients deserve. 


\section{References}

1. Bolognese L, Carrabba N, Parodi G, Santoro GM, Buonamici P, Cerisano G, et al. Impact of microvascular dysfunction on left ventricular remodeling and long-term clinical outcome after primary coronary angioplasty for acute myocardial infarction. Circulation. 2004;109:1121-6.

2. Bonow RO, Castelvecchio S, Panza JA, Berman DS, Velazquez EJ, Michler RE, et al; STICH Trial Investigators. Severity of remodeling, myocardial viability, and survival in ischemic LV dysfunction after surgical revascularization. JACC Cardiovasc Imaging. 2015;8:1121-9.

3. Hou L, Kim JJ, Woo YJ, Huang NF. Stem cell-based therapies to promote angiogenesis in ischemic cardiovascular disease. Am J Physiol Heart Circ Physiol. 2016;310:H455-65.

4. Chimenti I, Smith RR, Li TS, Gerstenblith G, Messina E, Giacomello A, et al. Relative roles of direct regeneration versus paracrine effects of human cardiosphere-derived cells transplanted into infarcted mice. Circ Res. 2010;106: 971-80.

5. Atluri P, Panlilio CM, Liao GP, Suarez EE, McCormick RC, Hiesinger W, et al. Transmyocardial revascularization to enhance myocardial vasculogenesis and hemodynamic function. J Thorac Cardiovasc Surg. 2008;135:283-91.e1; discussion 291.

6. Uchinaka A, Yoshida M, Tanaka K, Hamada Y, Mori S, Maeno Y, et al. Overexpression of collagen type III in injured myocardium prevents cardiac systolic dysfunction by changing the balance of collagen distribution. $J$ Thorac Cardiovasc Surg. 2018;156:217-26.e3.

7. Uchinaka A, Hamada Y, Mori S, Miyagawa S, Saito A, Sawa Y, et al. SVVYGLR motif of the thrombin-cleaved N-terminal osteopontin fragment enhances the synthesis of collagen type III in myocardial fibrosis. Mol Cell Biochem. 2015;408: 191-203.

8. Zhou Y, Singh AK, Hoyt RF Jr, Wang S, Yu Z, Hunt T, et al. Regulatory T cells enhance mesenchymal stem cell survival and proliferation following autologous cotransplantation in ischemic myocardium. J Thorac Cardiovasc Surg. 2014; 148:1131-7; discussion 1117 . 